\title{
Computational design of Oligo-sulfuranes
}

\author{
CHAKKINGAL P PRIYAKUMARI ${ }^{\mathrm{a}}$ and ELUVATHINGAL D JEMMIS ${ }^{\mathrm{b}, *}$ (D) \\ ${ }^{a}$ School of Chemistry, Indian Institute of Science Education and Research Thiruvananthapuram, CET \\ Campus, Thiruvananthapuram, Kerala 695 016, India \\ ${ }^{b}$ Department of Inorganic and Physical Chemistry, Indian Institute of Science, Bangalore, Karnataka 560012 , \\ India \\ e-mail: jemmis@ipc.iisc.ernet.in
}

MS received 7 June 2016; revised 11 August 2016; accepted 12 August 2016

\begin{abstract}
We studied the effect of electronegativity perturbation on the isolobal behavior of tetra-coordinate hypervalent compounds of $\mathrm{S}$ (sulfuranes, $\mathrm{SL}_{4}, \mathrm{~L}$ is any atom or group which can provide one electron for S-L bonding). Though formally the fragment $\mathrm{SL}_{4}$ obtained from $\mathrm{SL}_{6}$ is an isolobal equivalent of $\mathrm{CH}_{2}$, a qualitative molecular orbital study shows that only $\mathrm{SF}_{2} \mathrm{H}_{2}$ with equatorial $\mathrm{F}$ atoms is a practical isolobal substitute for $\mathrm{CH}_{2}$ and can form oligomers, $\left(\mathrm{SF}_{2} \mathrm{H}_{2}\right)_{2},(\mathbf{1 4}),\left(\mathrm{SF}_{2} \mathrm{H}_{2}\right)_{3},(\mathbf{1 5})$ and $\left(\mathrm{SF}_{2} \mathrm{H}_{2}\right)_{4},(\mathbf{1 6})$ analogous to ethylene, cyclopropane and cyclobutane, respectively. DFT computations at the B2PLYP/6-311++g(d,p), MP2/aug-cc$\mathrm{pVTZ}$ and B3LYP/6-311++g(d,p) levels confirm these structures to be minima on the PES. The skeletal S-S bonds in these structures are formed solely by the bonding combination of anti-bonding fragment orbitals of $\mathrm{SF}_{2} \mathrm{H}_{2}$. In contrast, per-fluorination, the usual way to stabilize hypervalent structures, is found to have an opposite effect here. Calculations at the same levels show $\left(\mathrm{SF}_{4}\right)_{2},\left(\mathrm{SF}_{4}\right)_{3}$, and $\left(\mathrm{SF}_{4}\right)_{4}$ not to be minima. The highly stable $\mathrm{HOMO}$ of $\mathrm{SF}_{4}$ fragment and large HOMO-LUMO gap makes $\mathrm{SF}_{4}$ a stable entity, preventing it from oligomerization. Out of the various isomers of $\mathrm{SF}_{\mathrm{n}} \mathrm{H}_{4-\mathrm{n}}, \mathrm{n}=0-4$, only $\mathrm{SF}_{2} \mathrm{H}_{2}$ with equatorial $\mathrm{F}$ atoms can form oligomeric sulfuranes. Substitution of $\mathrm{F}$ by heavier analogs of the group did not lead to any stable oligomers.
\end{abstract}

Keywords. Sulfuranes; isolobal analogy; oligo-sulfuranes; electronegativity perturbation.

\section{Introduction}

After a century of Lewis 2c-2e bond, hypervalent molecules that defy the rule still draw attention. ${ }^{1}$ This is especially so for cyclic molecules with hypervalent atoms. ${ }^{2}$ We present here an electronic structure study of a family of possible cyclic sulfuranes. Sulfuranes are well known synthetic reagents. ${ }^{3-10}$ The Martin sulfuranes, for example, are used for a variety of reactions like dehydration, amide cleavage, epoxide formation, etc. . $^{3-10}$ Sulfuranes with the exception of $\mathrm{SH}_{4},{ }^{11}$ have butterfly-like structure, which can be visualized as a trigonal bipyramid (TBP), with an equatorial vertex replaced by a lone pair (Figure 1). ${ }^{12,13}$ An analysis of the bonding in sulfuranes $\left(\mathrm{SL}_{4}, \mathrm{~L}=\right.$ any atom or group which can provide one electron for S-L bonding) has shown that electronegative substituents prefer to occupy the axial position, a behavior similar to that of TBPphosphorus. ${ }^{12,13}$ Thus, $\mathrm{SL}_{4}$ can be considered, both in terms of its geometry and substituent preferences, as originated from a TBP structure. An isolobal analysis of sulfuranes ${ }^{14}$ reveals some new aspects (Figure 2). If

*For correspondence

Celebrating 100 years of Lewis Chemical Bond
$\mathrm{SL}_{4}$ is considered to be originated from TBP $\mathrm{SL}_{5}^{+}, \mathrm{SL}_{4}$ is isolobal to $\mathrm{CH}_{3}^{-}$, which in turn implies that $\mathrm{PL}_{4}$ and the isoelectronic $\mathrm{SiL}_{4}^{-}$are isolobal to $\mathrm{CH}_{3}$ radical (Of course, this is not the right way to generate isolobal fragments, as we also need to worry about the symmetry and energy of the frontier orbitals; we will be taking care of those aspects later). Many compounds are known where $\mathrm{SiL}_{4}^{-}$dimerizes like $\mathrm{CH}_{3}$ radical. ${ }^{15-19}$ We looked at $\mathrm{SL}_{4}$ in a different perspective. If we consider $\mathrm{SL}_{4}$ as a fragment derived from $\mathrm{SL}_{6}$ (Figure 2), can it be isolobal to $\mathrm{CH}_{2}$ ? If so, can it form dimer, trimer etc., as $\mathrm{CH}_{2}$ does (Figure 3)? Our attempt to answer this question led to the prediction of a new class of compounds, oligo-sulfuranes. The study also revealed a strong dependence of the isolobal behavior of hypervalent fragments on the nature and position of substituents.

\section{Computational Details}

Computations at the B2PLYP/6-311++g(d,p) level were used to verify our predictions based on qualitative molecular orbital theory. ${ }^{20,21}$ The double hybrid density functional B2PLYP is an improvement over B3LYP by including perturbative second order correlation. ${ }^{21}$ 

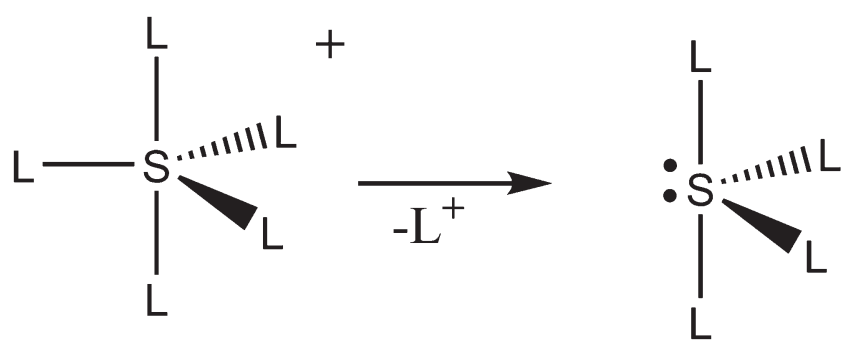

Figure 1. Formation of sulfurane $\left(\mathrm{SL}_{4}\right)$ from trigonal bipyramidal $\mathrm{SL}_{5}^{+}$.

Frequency analysis is done on the optimized geometries to locate minima on the potential energy surface. Computations were done also at the B3LYP/6-311++g(d,p) level and MP2/aug-cc-pVTZ level as well and the results are similar. ${ }^{22-25}$ For discussion, we use the results obtained from B2PLYP/6-311++g(d,p) level of computations. Coordinates and energies of the structures discussed are given in the Supporting Information.

\section{Results and Discussion}

Optimization of structures $\mathbf{2}$ and $\mathbf{3}$ with $\mathrm{L}=\mathrm{H}$, resulted in collapse to the sulfurane fragments. This prompted us to try $\mathrm{L}=\mathrm{F}$, as it is already known that $\mathrm{F}$ atoms can stabilize hypervalent structures and we have proposed an unusual system stabilized by $\mathrm{F}$ atoms, $\left(\mathrm{PF}_{3}\right)_{3}^{2-}{ }^{2}$ To our surprise, even perfluorination could not stabilize structures $\mathbf{2}$ and 3. This implies that we need to look into the details of frontier orbitals of sulfurane fragments and their isolobal relationships.

The frontier orbitals of $\mathrm{SH}_{4}$ (4) (Figure 4, b) shows that they have the same symmetry as the frontier
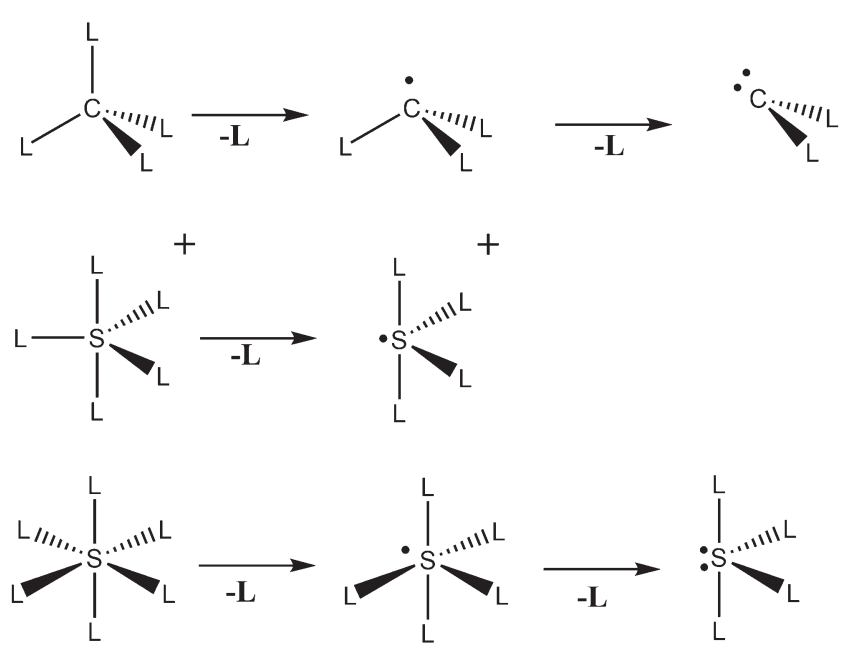

Figure 2. Formation of tetra-coordinate hypervalent fragment and their isolobal relationships to the fragments of $\mathrm{CH}_{4}$.<smiles>CS(C)(C)(C)(C)C</smiles>

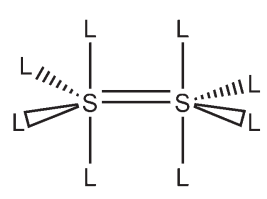

(2)

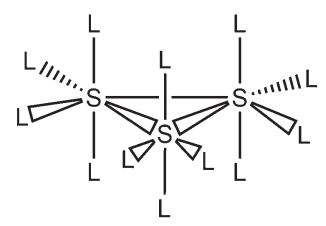

(3)
Figure 3. Formation of the oligomers of sulfuranes; L is any atom or group which can provide one electron for S-L bonding.

orbitals of $\mathrm{CH}_{2}$ (Figure 4, a), but energetically, the former must be higher in energy as they are anti-bonding orbitals (Refer Table 1 for the coefficients and energy values). The $\mathrm{SH}_{4}$ fragment is created by the removal of two $\mathrm{H}$ atoms from $\mathrm{SH}_{6}$ and $\mathrm{CH}_{2}$ fragment is created by the removal of two $\mathrm{H}$ atoms from $\mathrm{CH}_{4}$. This was done so, as the butterfly structure of $\mathrm{SH}_{4}$ cannot be obtained as a stationary point. The calculations are for singlet. The frontier orbitals of $\mathrm{CH}_{2}$ are localized over $\mathrm{C}$ atom, whereas in $\mathrm{SH}_{4}$ they are delocalized over $\mathrm{S}$ and $\mathrm{H}$ atoms. Thus, the interaction between the $\mathrm{S}$ atoms of two $\mathrm{SH}_{4}$ fragments will not be as stabilizing as the interaction between the $\mathrm{C}$ atoms of two $\mathrm{CH}_{2}$ fragments.

It is reasonable to assume that for any sulfurane to imitate $\mathrm{CH}_{2}$, there must be significant coefficient of the frontier orbitals on the $\mathrm{S}$ atom. The frontier orbital coefficient on $\mathrm{S}$ in sulfurane depends on the energy difference between the $\mathrm{S}$ atom orbitals and the Symmetry Adapted Linear Combination (SALC) which interact with it. This is represented schematically in Figure 5; the three situations, (1) the energy of SALC is very high

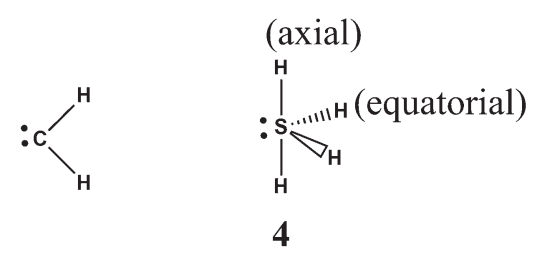

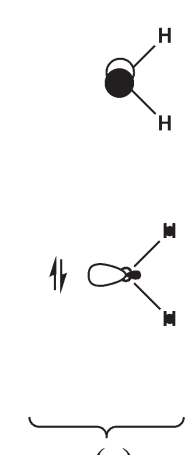

(a)
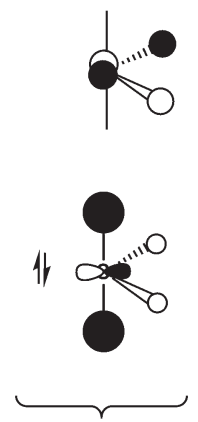

(b)

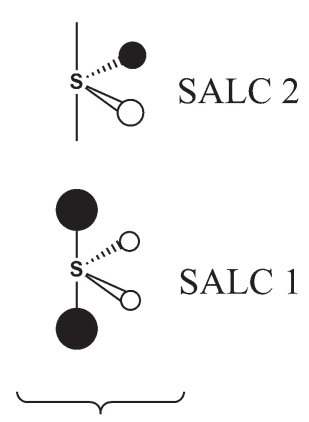

(c)
Figure 4. (a) Frontier orbitals of $\mathrm{CH}_{2}$ (singlet); (b) Frontier orbitals of $\mathrm{SH}_{4}$; (c) Symmetry Adapted Linear Combinations (SALCs) corresponding to the frontier orbitals of $\mathrm{SH}_{4}$. 
Table 1. Percentage contributions from the atomic orbitals to the frontier orbitals of 4-7 and their energy values in eV. Comparison to singlet $\mathrm{CH}_{2}$ is also shown.

\begin{tabular}{|c|c|c|c|c|c|}
\hline \multirow{2}{*}{$\stackrel{\circ}{\circ}$} & \multicolumn{2}{|c|}{ HOMO coefficient on $S$} & \multirow[t]{2}{*}{ LUMO coefficient on $S$} & \multirow[t]{2}{*}{ HOMO Energy/eV } & \multirow[t]{2}{*}{ LUMO energy/eV } \\
\hline & $\mathbf{s}(\mathbf{S})$ & $\mathbf{p}(\mathbf{S})$ & & & \\
\hline 4 & 0 & 15 & 19 & -5.5 & 0.5 \\
\hline 5 & 0 & 40 & 91 & -8.4 & -2.6 \\
\hline 6 & 20 & 32 & 15 & -10.2 & 0.1 \\
\hline 7 & 23 & 20 & 92 & -11.9 & -2.5 \\
\hline $\mathrm{CH}_{2}$ & & & & -8.3 & -1.8 \\
\hline
\end{tabular}

compared to the p orbitals of $\mathrm{S}$ atom (a \& d); (2) the energy of SALC is comparable to the p orbitals of $\mathrm{S}$ atom (b \& e); (3) the energy of SALC is lower than the p orbital of $S$ atom $(\mathbf{c} \& \mathbf{f})$, are shown. The large size of the orbitals in Figure 5 indicates large coefficients. The antibonding combinations in $\mathbf{a}, \mathbf{b}$ and $\mathbf{c}$, respectively, form the HOMO of the sulfurane when the energy of the SALC is $>,=$ or $<$ the energy of the p orbital in S. The diagrams are constructed based on the simple logic that the bonding MOs will have large coefficients from the lower energy fragment orbitals and the antibonding MOs will have large coefficients from the higher energy fragment orbital (the fragments in the sulfurane, $\mathrm{SL}_{4}$ are $\mathrm{S}$ and $\mathrm{L}_{4}$ ). To remind, a better comparison to the HOMO of singlet $\mathrm{CH}_{2}$ will be when the coefficient on $\mathrm{S}$ is large. Comparing the antibonding MOs in $\mathbf{a}, \mathbf{b}$ and c, one can immediately avoid $\mathbf{a}$, as the coefficient over $\mathrm{S}$ is less. The antibonding MO in case $\mathbf{c}$ has significant
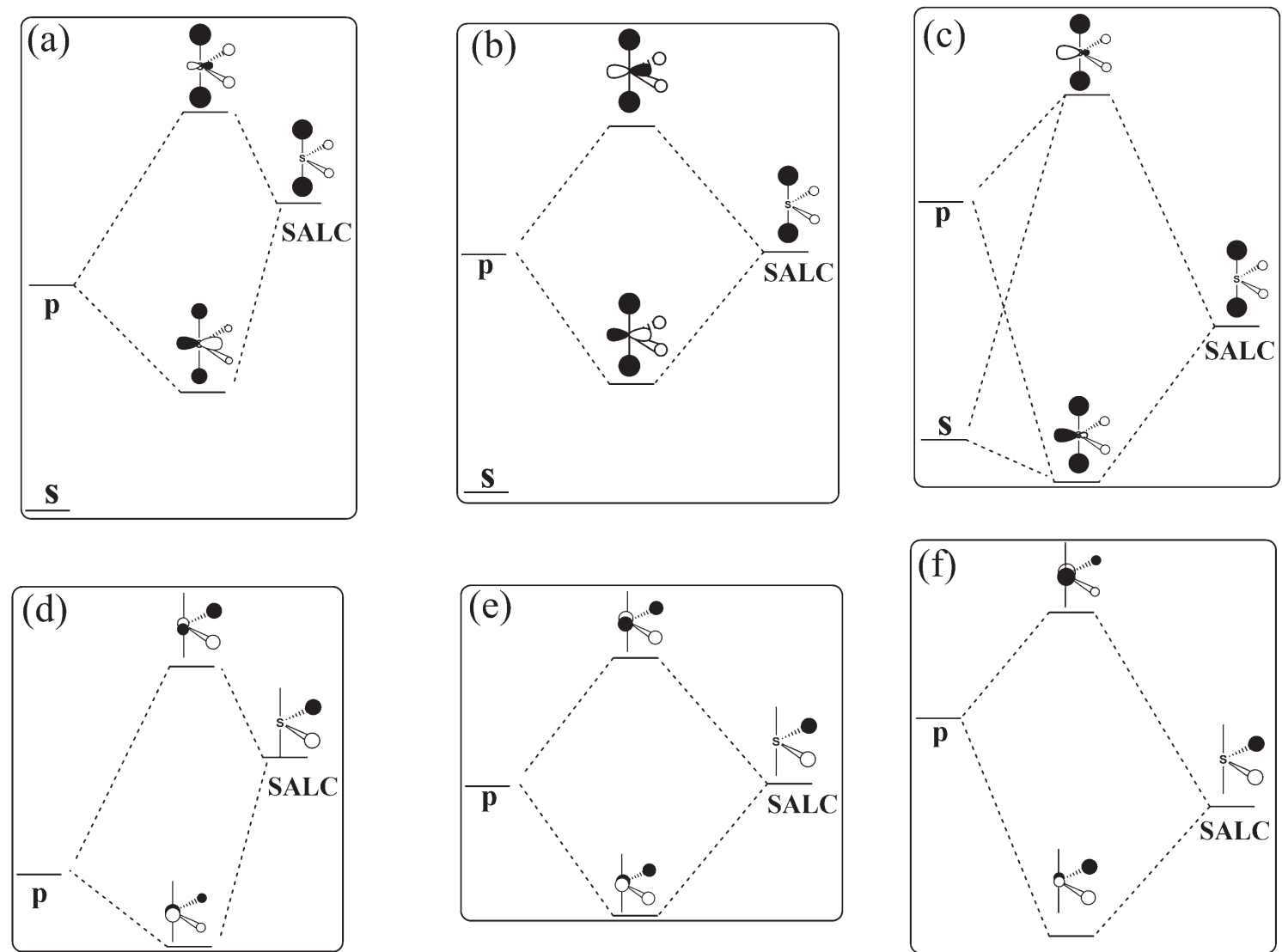

Figure 5. a, b and c- interaction of the SALC of sulfurane with the orbitals on S to form the bonding and antibonding combinations, where the antibonding one forms the HOMO of sulfurane. Diagrams $a, b$ and $c$ correspond to situations when the SALC energy is $>,=$ or $<$ the energy of the p orbital of S; d, e and finteraction of the SALC with the p orbital on $\mathrm{S}$ to form the bonding and antibonding combinations, where the antibonding one forms the LUMO of sulfurane. Diagrams d, e and f correspond to situations when the SALC energy is $>,=$ or $<$ the energy of the $p$ orbital of $S$. 


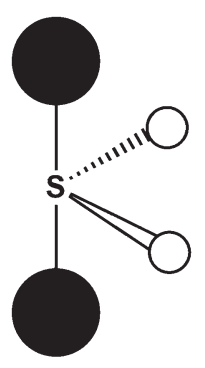

SALC1
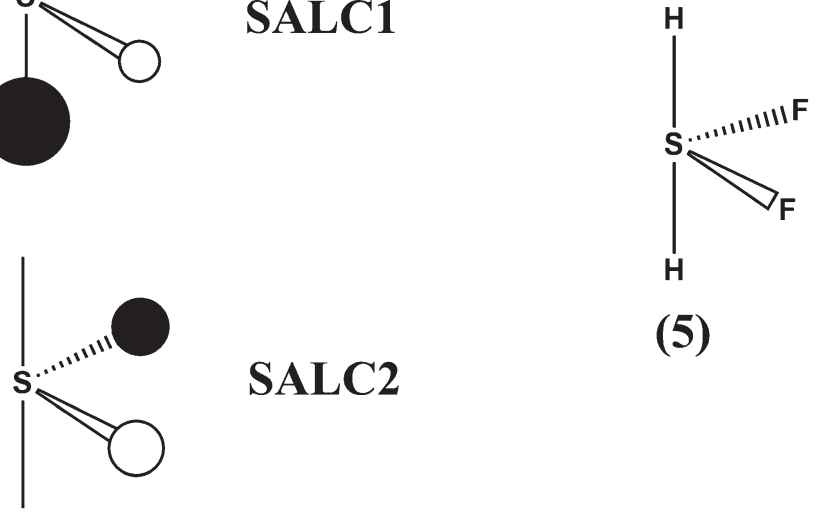

SALC2

(5)

Figure 6. The highest energy SALCs of sulfurane: Substitution of $\mathrm{F}$ atoms in the equatorial position slightly stabilizes SALC1 and significantly stabilizes SALC2.

coefficient over $\mathrm{S}$, but the large mixing of the s orbital will tend to make it inert. Thus, the antibonding MO in $\mathbf{b}$ remains as a reasonable comparison to the HOMO of $\mathrm{CH}_{2}$ (singlet). The antibonding combinations in $\mathbf{d}$, e and $\mathbf{f}$, respectively, form the LUMO of the sulfurane when the energy of the SALC is $>$, = or $<$ the energy of $\mathrm{p}$ orbital in $\mathrm{S}$. Comparing $\mathbf{d}$, e and $\mathbf{f}$, the antibonding combination in $\mathbf{f}$ seems to be the best comparison to the LUMO of $\mathrm{CH}_{2}$ (singlet) as the coefficient over $\mathrm{S}$ is maximum. The only thing we need to do now is to create the sulfurane in such a way that its HOMO resembles the antibonding combination in $\mathbf{b}$ and its LUMO resembles the antibonding combination in $\mathbf{f}$. That means a moderate stabilization of SALC1 and huge stabilization of SALC2 (Figure 6). How can this be achieved? If the high coefficient sites of SALC1 are occupied by F, it is highly stabilized. If the low-coefficient sites are occupied by F, it is moderately stabilized. Now, the SALC2 can be stabilized significantly by substituting $\mathrm{F}$ atoms in the equatorial position. Thus, $\mathrm{SF}_{2} \mathrm{H}_{2}$ with equatorial $\mathrm{F}$ atoms will be the best comparison to $\mathrm{CH}_{2}$.

The sulfuranes we considered are shown in Figure 7, so chosen, as to match the symmetry of $\mathrm{CH}_{2}$ and also to invoke electronegativity perturbation. Our qualitative arguments are difficult to support by quantitative diagrams or numbers because of several reasons: (1) Since there are lone pairs on F, which often mix with the radial orbital combinations, it is difficult to show a one-to-one relationship between the qualitative MO pictures and the computed MOs; (2) The sulfurane geometries considered are not the optimized geometries, they are constructed by the removal of adjacent $\mathrm{H}$ atoms from the corresponding persulfuranes, as indicated in Figure 7 (these persulfuranes were studied computationally by Steudel et $a l .{ }^{26}$ ). This was necessary, as the structures $\mathbf{4}$ and $\mathbf{5}$ cannot be obtained as stationary points after optimization. Nevertheless, we report here the computed frontier orbital coefficients and energy values of the sulfuranes 4-7 (Table 1). The correlation with the qualitative arguments is evident. The frontier orbital energy values of $\mathrm{CH}_{2}$ (singlet) and $\mathbf{5}$ are comparable. Thus, $\mathbf{5}$ seems to be the best isolobal substitute for $\mathrm{CH}_{2}$. Triplet state of 5 is a minimum and the energy values of the singly occupied orbitals are very close to those of triplet $\mathrm{CH}_{2}$ $\left(-9.5 \mathrm{eV},-8.5 \mathrm{eV}\right.$ for $\mathrm{CH}_{2}$ and $-9.6 \mathrm{eV},-8.3 \mathrm{eV}$ for $\mathrm{SF}_{2} \mathrm{H}_{2}$ ). On the other hand, the singlet state of $\mathbf{5}$ is not a stationary point; it converges to $\mathbf{6}$ during optimization. It was already shown computationally that the most stable structure of $\mathrm{SF}_{2} \mathrm{H}_{2}$ is $\mathbf{6}^{27,28}$ The large s character of the HOMO and the large HOMO-LUMO gap makes 6 and 7 stable molecules as such (Table 1). The computed frontier orbitals of all the sulfurane fragments considered, are shown in Figure 8, along with the frontier

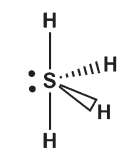

4
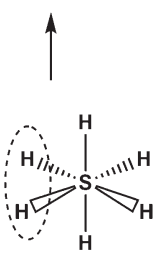

9

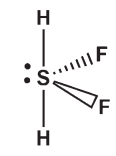

5
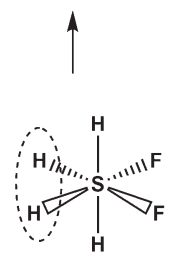

10

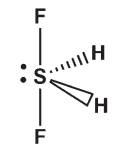

6
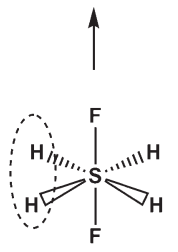

11
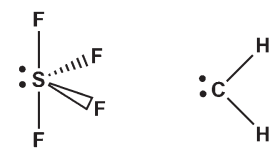

7
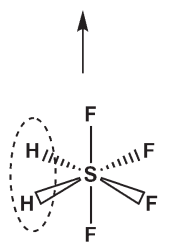

12
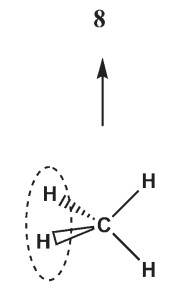

13

Figure 7. $\mathrm{SH}_{4}$ and $\mathrm{SF}_{\mathrm{n}} \mathrm{H}_{4-\mathrm{n}}$ with $\mathrm{C}_{2 \mathrm{v}}$ symmetry. They are constructed by the removal of adjacent $\mathrm{H}$ atoms (shown in dotted ellipse) from the corresponding persulfuranes. Comparison to $\mathrm{CH}_{2}$ formation from $\mathrm{CH}_{4}$ is also shown. 


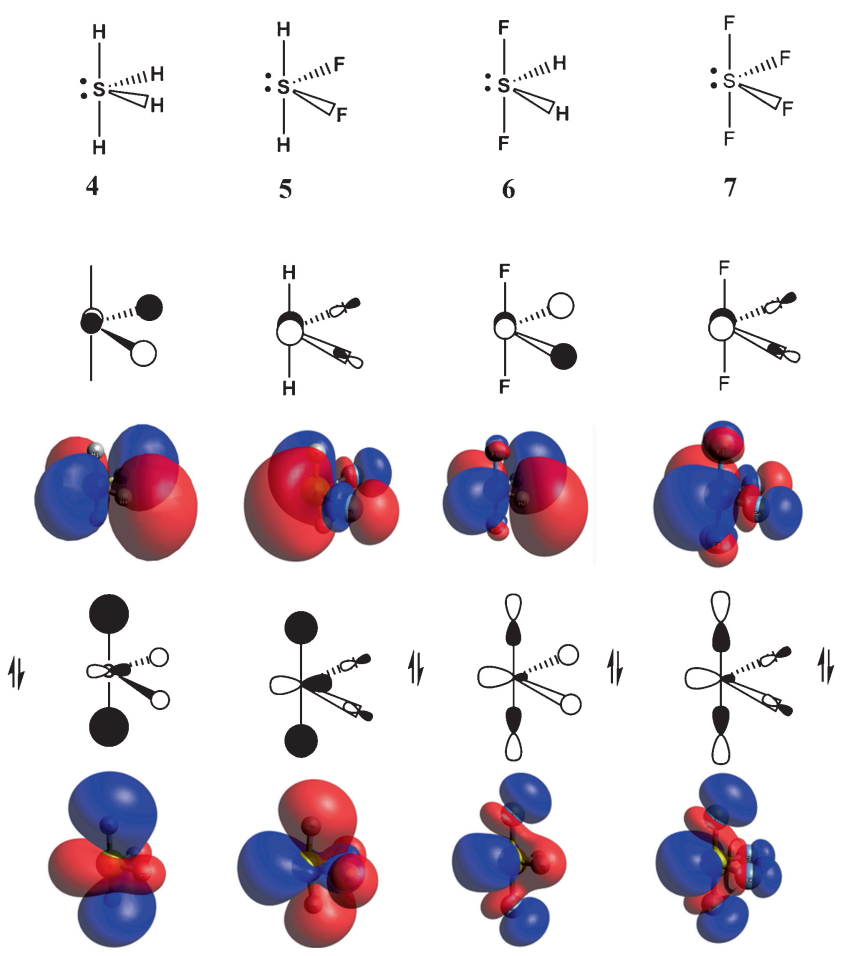

Figure 8. Comparison of the frontier orbitals of sulfuranes 4-7 computed, to those constructed by qualitative MO theory.

orbitals constructed based on the analysis shown in Figure 5. The actual picture looks slightly different in the case of the HOMOs of $\mathbf{6}$ and 7. The HOMOs of $\mathbf{6}$ and 7 can be better described by an interaction as shown in Figure 9.

In agreement with the previous analysis, the sulfuranes, 4, 6, 7 and $\mathrm{SF}_{2} \mathrm{H}_{2}$ with one equatorial and one axial F, which are not good isolobal analogs of $\mathrm{CH}_{2}$ could not form structures similar to $\mathbf{2}$ and $\mathbf{3}$. On the other hand, structure $\mathbf{5}$, which is shown to be a better isolobal analog of $\mathrm{CH}_{2}$, gave dimeric and oligomeric structures as minima, analogous to ethylene and cycloalkanes (Figure 10). Oligomeric structures with $\mathrm{F}$ atoms replaced by other halogens are not minima, as with other halogens the antibonding coefficient on $\mathrm{S}$ decreases (the electronegativity perturbation will be less with other halogens). The $\mathrm{S}-\mathrm{S}$ bond length in the dimeric structure, $\left(\mathrm{SF}_{2} \mathrm{H}_{2}\right)_{2}(\mathbf{1 4})$ is $1.955 \AA$, which is close to the $\mathrm{S}-\mathrm{S}$ bond length of $\mathrm{S}_{2}(1.926 \AA)$ calculated at the same level. The HOMO-LUMO gap is $8.5 \mathrm{eV}$. The trimeric sulfurane, $\left(\mathrm{SF}_{2} \mathrm{H}_{2}\right)_{3}(\mathbf{1 5})$ analogous to cyclopropane, is a minimum with a HOMO-LUMO gap of $8.2 \mathrm{eV}$; the $\mathrm{S}$-S bond length is $2.222 \AA$. The tetrameric sulfurane, $\left(\mathrm{SF}_{2} \mathrm{H}_{2}\right)_{4}(\mathbf{1 6})$ is also found to be a minimum with a HOMO-LUMO gap of $7.7 \mathrm{eV}$ and an S-S bond length of $2.271 \AA$. Its puckered structure is similar to that of cyclobutane.

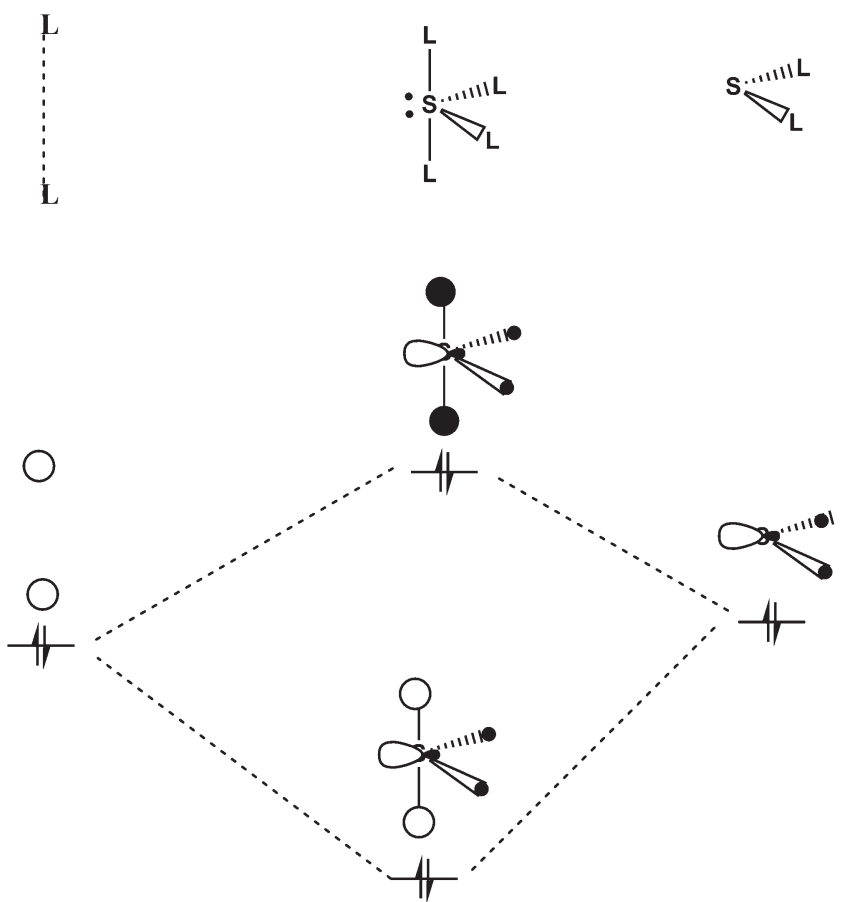

Figure 9. Interaction of the $\mathrm{SL}_{2}$ fragment with $\mathrm{L} 2$ to generate $\mathrm{SL}_{4}$; only the interaction of the radial orbital of SL2 is shown; The antibonding combination is similar to the HOMO of $\mathbf{6}$ and $\mathbf{7}$ obtained by computations.

The binding energy of the structures 14-16 with respect to the triplet $\mathrm{SF}_{2} \mathrm{H}_{2}$ fragments $\left(\mathrm{E}\left(\left(\mathrm{SF}_{2} \mathrm{H}_{2}\right)_{\mathrm{n}}\right)\right.$ $\left.\mathrm{nE}\left(\mathrm{SF}_{2} \mathrm{H}_{2}\right)\right)$ are $-53.2 \mathrm{kcal} / \mathrm{mol},-72.6 \mathrm{kcal} / \mathrm{mol}$ and $-101.0 \mathrm{kcal} / \mathrm{mol}$, respectively, at $298.15 \mathrm{~K}$. These large negative values indicate thermodynamic stability with respect to the dissociation into $\mathrm{SF}_{2} \mathrm{H}_{2}$ fragments. Thus, the fragmentation of oligo-sulfuranes to $\mathrm{SF}_{2} \mathrm{H}_{2}$ fragments will be difficult. But other lower energy fragmentation paths are possible which generates multiple fragments and involves elimination of $\mathrm{H}_{2}$ or $\mathrm{HF}$ (the transition states and the Intrinsic Reaction Coordinate (IRC) plots are given in the Supporting Information). The barrier for dissociation through these lower energy pathways for di-, tri- and tetramers of $\mathrm{SF}_{2} \mathrm{H}_{2}$ are 5.2 $\mathrm{kcal} / \mathrm{mol}, 10.2 \mathrm{kcal} / \mathrm{mol}$ and $9.9 \mathrm{kcal} / \mathrm{mol}$, respectively, which are very small, thereby making the experimental realization of these molecules very difficult. In spite of that, these barriers are enough for their fleeting existence in low temperature matrices. ${ }^{29}$ Structures 14-16 are model systems which show the utility of qualitative MO theory to predict new bonding patterns. An experimental realization would require severe stabilizing methods. Higher homologues like $\left(\mathrm{SF}_{2} \mathrm{H}_{2}\right)_{5},\left(\mathrm{SF}_{2} \mathrm{H}_{2}\right)_{6}$, etc., are also minima (See Supporting Information for the coordinates of $\left(\mathrm{SF}_{2} \mathrm{H}_{2}\right)_{5}$ and $\left.\left(\mathrm{SF}_{2} \mathrm{H}_{2}\right)_{6}\right)$, though the proximity of the atoms would make them highly unstable. 


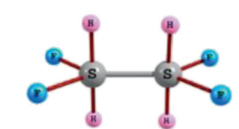

14
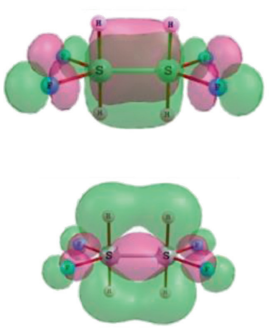

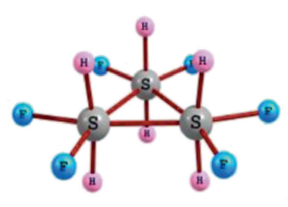

15

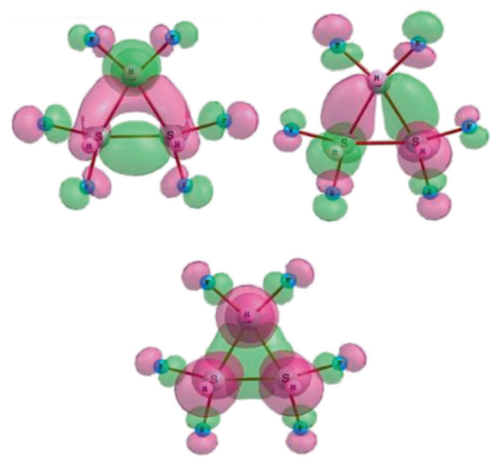

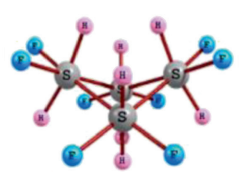

16

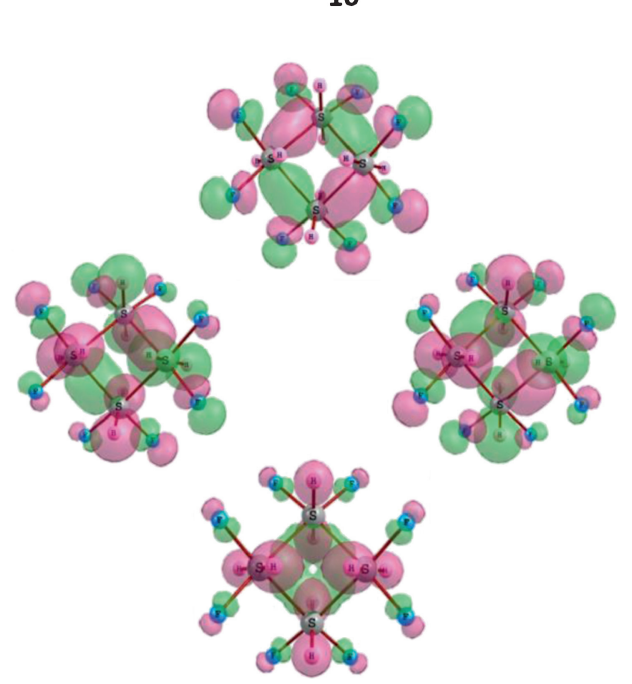

Figure 10. $\left(\mathrm{SF}_{2} \mathrm{H}_{2}\right)_{\mathrm{n}}(\mathrm{n}=2,34)$ and the $\mathrm{S}-\mathrm{S}$ bonding MOs; blue spheres are $\mathrm{F}$ and pink spheres are $\mathrm{H}$.

The entry of anionic oligomers of $\mathrm{CO}$ and $\mathrm{PF}_{3}$ in literature showed us examples for skeletal bonding involving fragment antibonding orbitals. ${ }^{2,30}$ In these molecules, one fragment orbital is the radial nonbonding orbital and the other is antibonding orbital. The unusual feature of structures 14-16, is that both of their fragment frontier orbitals are antibonding; no surprise that they are less stable kinetically. Thus, these molecules form a unique class of compounds, where the oligomeric skeleton is formed solely by the monomeric $\sigma^{*}$ and pseudo- $\pi^{*}$ orbitals. Similar bonding is noted in the pancake-type $\pi$-stacking interactions, where $\pi^{*}$ orbitals of two molecules interact. ${ }^{31}$

The isolobal analogy in the transition metal fragments depends less on the substituents on the transition metal. The $\mathrm{ML}_{4}$ fragment ( $\mathrm{M}$ is a transition metal) generated from $\mathrm{ML}_{6}$, can be equated to $\mathrm{CH}_{2}$ fragment if the frontier orbital of $\mathrm{ML}_{4}$ has 2 electrons. On the other hand, the $\mathrm{SH}_{4}$ fragment generated from $\mathrm{SH}_{6}$ is not isolobal to $\mathrm{CH}_{2}$. Out of the various isomers of $\mathrm{SF}_{n} \mathrm{H}_{4-n}$ $(\mathrm{n}=0-4), \mathrm{SF}_{2} \mathrm{H}_{2}(\mathbf{5})$ is the only structure that can form oligomers as $\mathrm{CH}_{2}$ does. Thus the isolobal behavior of hypervalent fragments depends strongly on the nature and position of the substituents.

\section{Conclusions}

We have analyzed the isolobal behavior of sulfurane fragments based on qualitative molecular orbital theory and electronegativity perturbation. We show that $\mathrm{SF}_{2} \mathrm{H}_{2}$ with equatorial $\mathrm{F}$ atoms is a good isolobal substitute for $\mathrm{CH}_{2}$. Thus, the oligo-sulfuranes, $\left(\mathrm{SF}_{2} \mathrm{H}_{2}\right)_{2},\left(\mathrm{SF}_{2} \mathrm{H}_{2}\right)_{3}$ and $\left(\mathrm{SF}_{2} \mathrm{H}_{2}\right)_{4}$, are minima, and form the hypervalent analogs of ethylene, cyclopropane and cyclobutane. The skeletal S-S bonding orbitals in these structures are formed from the $\mathrm{SF}_{2} \mathrm{H}_{2}$-antibonding orbitals. Since the large electronegativity perturbation induced by $\mathrm{F}$ atoms is responsible for their stability, structures with other halogen atoms are not minima. Contrary to typical hypervalent structures which are stabilized by per-fluorination, oligo-sulfuranes decompose on perfluorination; $\left(\mathrm{SF}_{4}\right)_{2},\left(\mathrm{SF}_{4}\right)_{3}$ and $\left(\mathrm{SF}_{4}\right)_{4}$ are not minima. Thus, we show that it is possible to stabilize hypervalent structures, which are quite unstable otherwise, by properly adjusting the positions of electronegative atoms, so as to create orbitals of proper symmetry.

\section{Supplementary Information (SI)}

Coordinates of the structures are given in the Supporting Information, available at www.ias.ac.in/chemsci.

\section{Acknowledgements}

CPK and EDJ thank IISER Thiruvananthapuram, IISc Bangalore and CMSD, University of Hyderabad for providing computational facilities. CPK thanks CSIRIndia for research fellowship. DST is acknowledged for the J C Bose fellowship to EDJ. 


\section{References}

1. Lewis G N 1916 J. Am. Chem. Soc. 38762

2. Priyakumari C P and Jemmis E D 2013 J. Am. Chem. Soc. 13516026

3. Pooppanal S S 2009 Synlett 2009850

4. Adzima L J, Chiang C C, Paul I C and Martin J C 1978 J. Am. Chem. Soc. 100953

5. Franz J A and Martin J C 1975 J. Am. Chem. Soc. 97583

6. Perozzi E F, Martin J C and Paul I C 1974 J. Am. Chem. Soc. 966735

7. Martin J C and Perozzi E F 1974 J. Am. Chem. Soc. 96 3155

8. Martin J C, Franz J A and Arhart R J 1974 J. Am. Chem. Soc. 964604

9. Franz J A and Martin J C 1973 J. Am. Chem. Soc. 95 2017

10. Arhart R J and Martin J C 1972 J. Am. Chem. Soc. 94 5003

11. Wittkopp A, Prall M, Schreiner P R and Schaefer III H F 2000 Phys. Chem. Chem. Phys. 2239

12. Chen M M L and Hoffmann R 1976 J. Am. Chem. Soc. 981647

13. Hoffmann R, Howell J M and Muetterties E L $1972 \mathrm{~J}$. Am. Chem. Soc. 943047

14. Hoffmann R 1982 Angew. Chem., Int. Ed. Engl. 21711

15. Zaitsev K V, Churakov A V, Poleshchuk O K, Oprunenko Y F, Zaitseva G S and Karlov S S 2014 Dalton Trans 436605

16. Kano N, Tsukada S, Shibata Y, Kawashima T, Sato H, Guo J-D and Nagase S 2014 Organometallics 3456

17. Kano N, Sasaki K, Miyake H and Kawashima T 2014 Organometallics $\mathbf{3 3} 2358$

18. Kano N, Miyake H, Sasaki K, Kawashima T, Mizorogi $\mathrm{N}$ and Nagase S 2010 Nat. Chem. 2112

19. Kano N, Nakagawa N, Shinozaki Y, Kawashima T, Sato Y, Naruse Y and Inagaki S 2005 Organometallics 24 2823
20. Frisch M J, Trucks G W, Schlegel H B, Scuseria G E, Robb M A, Cheeseman J R, Scalmani G, Barone V, Mennucci B, Petersson G A, Nakatsuji H, Caricato M, Li X, Hratchian H P, Izmaylov A F, Bloino J, Zheng G, Sonnenberg J L, Hada M, Ehara M, Toyota K, Fukuda R, Hasegawa J, Ishida M, Nakajima T, Honda Y, Kitao O, Nakai H, Vreven T, Montgomery J A, Peralta Jr. J E, Ogliaro F, Bearpark M, Heyd J J, Brothers E, Kudin K N, Staroverov V N, Kobayashi R, Normand J, Raghavachari K, Rendell A, Burant J C, Iyengar S S, Tomasi J, Cossi M, Rega N, Millam J M, Klene M, Knox J E, Cross J B, Bakken V, Adamo C, Jaramillo J, Gomperts R, Stratmann R E, Yazyev O, Austin A J, Cammi R, Pomelli C, Ochterski J W, Martin R L, Morokuma K, Zakrzewski V G, Voth G A, Salvador P, Dannenberg J J, Dapprich S, Daniels A D, Farkas Ö, Foresman J B, Ortiz J V, Cioslowski J and Fox D J, 2009 Gaussian 09, Revision D.01 (Gaussian, Inc.: Wallingford CT)

21. Grimme S 2006 J. Chem. Phys. 124034108

22. Becke A D 1993 J. Chem. Phys. 985648

23. Kendall R A, Dunning T H and Harrison R J 1992 J. Chem. Phys. 966796

24. Dunning T H 1989 J. Chem. Phys. 901007

25. Head-Gordon M, Pople J A and Frisch M 1988 J. Chem. Phys. Lett. 153503

26. Steudel Y and Steudel R 2003 Eur. J. Inorg. Chem. 2003 3798

27. Ignat'ev I S and Schaefer H F 1992 J. Phys. Chem. 96 6247

28. Gleiter R and Veillard A 1976 Chem. Phys. Lett. 3733

29. Hoffmann R, Schleyer P v R and Schaefer H F 2008 Angew. Chem., Int. Ed. 477164

30. Bao X, Zhou X, Lovitt C F, Venkatraman A, Hrovat D A, Gleiter R, Hoffmann R and Borden W T 2012 J. Am. Chem. Soc. 13410259

31. Cui Z-h, Lischka H, Beneberu H Z and Kertesz M 2014 J. Am. Chem. Soc. 13612958 